\title{
La participación de la mujer tunecina en la construcción de la paz: participación relevante en la transición democrática. ${ }^{1}$
}

The participation of Tunisian women in the construction of peace: relevant participation in the democratic transition.

Faicel Chaabani Chaabani

Graduado en Master Cultura de

Paz, Conflictos, Educación y

DDHH.

fa.chaabanicha@alum.uca.es

\section{Resumen}

Pocos meses después de conseguir la Independencia del país el 20 de marzo de 1956 (Zeyneb Farhat: 2005), se llevó a cabo nuevas rectificaciones con el fin de modernizar y, fomentar las bases de la primera república siguiendo los modelos europeos. Nuevas rectificaciones que tocan todos los sectores sobre todo el ámbito legislativo del Estado, tal vez, la constitución inspirada de las constituciones occidentales, códigos sociales, penales... entre otros. En el mismo año se promulga el Código de Estatuto Personal que otorga muchos derechos para la mujer que sigue siendo, como plataforma legislativa la más revolucionaria en el mundo árabe y musulmán.

El presente artículo propone un análisis documental de la participación de la mujer tunecina en la construcción de la paz después de la primavera árabe.

\section{Abstrac}

A few months after obtaining the Independence the 20 of March of 1956, new rectifications were carried out in order to modernize and promote the foundations of the first republic, following European models, new rectifications that touch all sectors on all especially legislative sphere of the state, taking the example of the Tunisian constitution which inspired from the Western constitutions, social codes, penal codes ... among others. In the same year

${ }^{1}$ Recibido: 19/05/2018 Evaluado: 23/06/2018 Aceptado: 25/06/2018 
the Code of Personal Status was promulgated giving many rights to the women who remain, till now as the legislative platform the most revolutionary in the Arab and Muslim world.

This article proposes a documentary analysis of the participation of the Tunisian women in the construction of peace after the Arab Spring.

Palabras clave: Código de Estatuto Personal, Emancipación, Primavera Árabe, Transición Democrática.

Keywords: Code of Personal Status, emancipation, Arabic Spring, Democratic Transition.

\section{Proceso de emancipación de la mujer tunecina hasta la actualidad}

De entrada, es bueno recordar que el actual Túnez, antes llamaba "Cartago" era uno de los países más potentes del Mediterráneo, fue fundado por una mujer que se llamaba "Alisa" (Kamel Sahli, 2001) que encabezó un grupo de comerciantes fenicios que se trasladaron del actual "Líbano" al norte de África construyendo el imperio en 814 antes de Cristo. Otra mujer, figura que enmarcó su presencia a lo largo de la historia, la más célebre en el país por sus hazañas, generosidad y su solidaridad con los colectivos desfavorecidos, fue la princesa Aziza Othmana (1606 - 1669), que según Kamel Sahli construyó un hospicio para los pobres y un refugio para los animales "construyó un hospicio para los pobres y un refugio para los perros y gatos callejeros, adelantando así y con muchos siglos las modernas asociaciones de protección de los animales." (Kamel Sahli, 2001)

En el mundo islámico en general y árabe en particular la situación de la mujer tunecina es diferente en muchos aspectos en comparación con el resto de mujeres del mundo árabe porque se benefició y sigue beneficiando de una plataforma legislativa que la permitió gozar de muchos derechos igual al hombre. En este contexto, ha habido otras circunstancias y personalidades y han influido en el proceso de emancipación. A mediados del siglo pasado se ha seguido una política emancipadora a favor de la mujer tunecina, el protagonista de esta política fue "Habib Burguiba" presidente del Estado tunecino desde 1956 hasta 1987.

Pero, ante todo, históricamente había otra figura más conocida en Túnez que era el escritor "Taher Haddad" que apeló a la emancipación de la mujer y, la escolarización de las niñas además de otras reivindicaciones a favor de la mujer. Tradujo estas ideas en un libro denominado "Nuestra Mujer en la Shariaa y la religión" que, tras ser publicado, levantó grandes críticas en contra por sus contenidos y, su interpretación del Corán.

La nueva posición de la mujer tunecina tiene que ver con este marco legislativo y, esta base popular tan extensa que llamó a su emancipación en un ámbito caracterizado por un retraso en la materia. La conciencia también del colectivo político se considera una de las bases 
relevantes para lograr dicho cambio que toca los sectores más sensibles del Estado en aquella época.

Cabe distinguir, que la mujer tunecina estaba entre dos posturas o tendencias muy diferentes, una clásica de los reformistas que seguía una línea protectora de la mujer contra las civilizaciones y culturas occidentales y, otra moderna, totalmente diferente que intentaba abrir lazos con occidente y, seguir este modelo en las libertades y derechos de la mujer para conseguir progresos. (Rosario Montoro Murillo, 1992).

Con el objetivo de promover la emancipación y la liberación de la mujer tunecina y llevar a cabo su participación en el desarrollo económico, social, político entre otros, se otorgó el Código de Estatuto Personal, que suponía un gran avance y un progreso importante en lograr los derechos de la mujer tunecina.

Este Código que ha sufrido 10 modificaciones desde su promulgación hasta la actualidad, estipulando puntos en algunos casos polémicos en referencia a la religión Islámica (derecho maliki), así como la abolición de la poligamia (art. 18), en esta condición la ley deja claro que la pareja debe estar libre en cualquier relación matrimonial y, en caso contrario se impone una sanción según la ley. En la misma línea se otorga el derecho al aborto (art. 35) que se puede practicar en ciertas condiciones durante los tres primeros meses, se permite sobre todo, por motivos de salud. La ley de aborto entró en vigor en 1973.

Otro asunto más polémico, que enmarca su presencia en el Código de Estatuto Personal, es el de la ley de herencia (art. 85) que se inspira en la ley coránica que otorga al hombre heredar el doble de la mujer y, en este marco se calcula la suma de ingresos y, de herencia en general dividiéndola entre los miembros de la familia, pero otorgando mayor cantidad a los hombres que a las mujeres.

Estos son los principales puntos del código aparte de otros derechos políticos, sociales, económicos, culturales... tales como, su seguridad social, derecho al divorcio (art. 30), acceso a la vida pública, derecho al voto, libertades personales, escolarización de la mujer, libertad de asociación y agrupación... entre otros.

Para llevar a cabo su participación en la vida social, económica, política y, promover su emancipación se han creado muchas asociaciones feministas desde la independencia hasta la actualidad como son: "Union Nationale des Femmes de Tunisie (U.N.F.T.)" (Unión Nacional de Mujeres de Túnez) creada en 1956 y presidida por Raddiya Haddad, su misión era consolidar la integración de la mujer en la sociedad. El principio asociativo de la mujer tunecina tuvo sus raíces a principios de los años treinta del pasado siglo, cuando se fundó en 1936 la "Union Musulmane des Femmes de Tunisie (U.M.F.T.)", (la Unión Musulmana de Mujeres de Túnez).

En este contexto y, durante los años siguientes dio lugar al surgimiento de otras asociaciones y organismos con el fin de promover y apoyar la participación de la mujer en los diferentes sectores del Estado, así como "Asociación Democrática de Mujeres Tunecinas", "Asociación de las Mujeres Jueces" que cuenta con un número tan elevado de jueces de sexo femenino que representan $60 \%$ de la totalidad de los jueces en el país. Además de otras 
asociaciones que tienen los mismos objetivos y principios que son la promoción de la participación de la mujer en la vida socio-política y, fomentar los derechos de sí misma, como el "Centro de Investigación, documentación e información sobre la mujer".

Más allá, en los años noventa del siglo pasado se creó el "Ministerio de Mujeres y Asuntos Familiares", con el fin de defender y apoyar los derechos de este colectivo y elaborar proyectos para mejorar la situación de la mujer.

\section{Datos significativos de la presencia feminista en los diferentes sectores del Estado}

Esta plataforma legislativa favoreció un ambiente adecuado para que la mujer tunecina pudiera sumergirse y actuar en los diferentes sectores junto al hombre, participando tanto en la vida política como económica, encabezando los sectores tan sensibles del Estado, ocupando los puestos directivos de grandes empresas, ministerios y organizaciones. La emancipación de la mujer dio frutos a partir de los años setenta cuando se registró una tasa de escolarización que supera los 40\% en comparación con la de los años sesenta que se limitaba en el 15\% según la confirmación del autor, en el ámbito escolar la presencia femenina aumentó considerablemente en estos años "En 1956 el alumnado femenino representaba el quince por ciento del conjunto de la población escolar y estudiantil, mientras que en 1975 representaba casi el cuarenta por ciento en primaria” (Rosario Montoro Murillo, 1992).

Más allá, las recientes estadísticas del Instituto Nacional de Estadísticas de Túnez destacan que la tasa de analfabetismo de las mujeres disminuyó hasta el 31\% en 2004 desde 1996 que había una tasa del 96\%.

La misma fuente asegura que la tasa de analfabetismo en general bajó de 23,3\% en 2004 a $18,8 \%$ en 2014 , pero aseveró que la tasa de analfabetismo de las niñas es más alta con $25 \%$ mientras $12,4 \%$ de los varones.

En el campo laboral, el porcentaje de inserción de las mujeres en la vida activa ha aumentado $\mathrm{y}$, han podido acceder al mercado laboral especialmente en sectores como la agricultura, industria, sanidad, transporte.... En 1960 la mujer solo representaba 5\% de la población activa mientras en 1980 llegó a alcanzar el 20\% de la población activa. (Rosario Montoro Murillo, 1992).

Catorce años después, este porcentaje ha aumentado de manera notable hasta llegar en 1994 a $25 \%$ de la población activa, distribuidas especialmente al sector de servicios. Se estima que $44 \%$ de las mujeres registradas trabajan en el sector agrícola, el mismo porcentaje, es decir $44 \%$ trabajan en sector industrial (textil) y $46.15 \%$ en el sector sanitario. Es bueno mencionar que, en verdad, estas estadísticas priorizan la situación de la mujer que ha marcado un gran avance en los últimos años evolucionando hacia una sociedad que da tanta importancia al sexo femenino como al masculino, convirtiendo a Túnez en uno de los países feministas en el mundo islámico y africano. Aun así, las estadísticas muestran que la mujer tunecina cuenta con muchas carencias todavía. 
Es interesante observar otras fuentes de opinión que tratan la situación de la mujer tunecina, donde se reflejan episodios de la participación feminista en la vida política y social del país (por ejemplo, diarios de opinión como "El Mundo"). No se han notado muchos sesgos en los datos y porcentajes. En un artículo titulado "Luces y sombras de la mujer tunecina", publicado en "El Mundo", Paka Díaz, asevera que la situación jurídica de la mujer tunecina es excepcional en los países árabes. La creciente presencia de la mujer alcanza el $40 \%$ de los abogados y con porcentaje menor en los jueces, tan solo $29.9 \%$, lo cual representa un tercio de los mismos, aunque en 1969 se nombró a la primera jueza. El sector sanitario registra un porcentaje alto de las farmacéuticas que supera el $72 \%$ y un porcentaje más modesto de periodistas pues tan solo representa 44\%. En la vida universitaria el porcentaje de mujeres registradas es alrededor de 60\%. Según la misma fuente, más de 1800 mujeres dirigen empresas. Estas cifras y otras determinan la imagen de la mujer y su presencia sustancial en los diferentes sectores vitales del Estado, aunque escondan otra realidad la de la mujer rural, en un país que fue clasificado entre los países democráticos que reconocen los derechos humanos, así como los derechos de la mujer.

A pesar de estos logros realizados durante años y años como fruto de mucho esfuerzo y trabajo de varios grupos sociales que han mostrado su apoyo e impulso a favor de la emancipación de la mujer, este colectivo sufre situaciones de desigualdad y discriminación salarial. Cabe señalar que, en el sector privado, los activistas sociales y defensores de los derechos de los trabajadores han levantado numerosas críticas y denuncias contra los dueños de estas empresas a la Unión General de Trabajo Tunecina (UGTT). A pesar de que la ley tunecina estipula obviamente la igualdad salarial entre ambos sexos y que el Estado firmó en 1951 la convención que trata la igualdad de los sueldos de ambos sexos, las desigualdades salariales siguen existiendo sobre todo en los sectores agrícola e industrial, donde se ha registrado un bajo control por parte del Estado y sus instituciones legítimas.

\section{Participación de la mujer tunecina en la primavera árabe}

Desde el estallido de los levantamientos en varios países del Norte de África y Asia, se han producido muchas críticas contra los gobiernos y reivindicaciones, para el fomento de las libertades y los derechos de las personas sin distinción alguna, derrocar a los gobiernos y a los regímenes que habían estado en el poder desde hace décadas, mejorar la situación económica de los pueblos...entre otras. La mujer tunecina ha mostrado su interés en participar en dicha revolución, ha encabezado las protestas, se ha enfrentado con la policía luchando para conseguir sus propósitos y luchado contra las corrientes que anteriormente negaban su condición.

La mujer tunecina salió a la calle protestando y desfiló junto al hombre contra la dictadura de Ben Ali, considerando que la lucha es la única vía para obligar al régimen para que lleve a cabo reformas y rectificaciones a favor de la mujer. Ella misma ha estado en las calles, plazas, avenidas como la de Habib Burguiba (símbolo de la revolución) ubicada en el corazón de la capital Túnez. Ha mostrado presencia activa y masiva en la sociedad civil, confirmando que este colectivo goza desde hace décadas de libertad de expresión y de trabajo. Esta realidad se contradice con la afirmación de Jesus Mosterin, cuando expresa tan solo el ejemplo de la mujer egipcia. Así, dice que "en el mundo islámico resulta casi imposible a las mujeres levantar la cabeza y criticar abiertamente la opresión que sufren, aunque alguna, 
como la feminista egipcia Nawal El Saadawi, lo ha intentado" (Jesus Mosterin, 2012). En este ámbito la mujer tunecina ha sido pionera $\mathrm{y}$, ha mostrado esta valentía durante décadas de lucha contra la tiranía y despotismo de los dictadores y, su inserción en la vida pública ha sido fruto de mucho trabajo y esfuerzo.

La mujer tunecina ha jugado una doble función, la primera consiste en la participación al mismo nivel que el hombre, por ejemplo, en las protestas y manifestaciones organizadas contra el régimen aprovechando el ciberespacio para motivar a muchas otras para que saliesen a las calles. La segunda consiste en una función directiva, es decir, dirigir manifestaciones, elaborar estrategias, prestar ayuda a los manifestantes como la distribución de comida, medicamentos... (Randa Achmawi, 2011)

En Túnez, la presencia de la mujer fue alta, gracias a los medios de comunicación que a su vez se usaron como instrumentos para transmitir mensajes, fotos, imágenes, videos... al mundo entero sobre las manifestaciones y protestas ocurridas que han llamado la atención dentro y fuera del país contra la tiranía y la injusticia. Como se ha dicho anteriormente, por medio de las redes sociales se hizo más fácil la difusión y la circulación de los videos... lo que aceleró la caída del régimen. Una de las mujeres que protagonizó las manifestaciones fue "Lina Ben Mehenni" que compartió videos en los cuales apeló a los y las jóvenes a salir a las calles, difundiendo imágenes sobre los acontecimientos ocurridos en Túnez en aquel periodo.

Tanto durante la revolución como después, la mujer tunecina se ha implicado de manera directa o indirecta en el proceso de cambio del panorama político, no solo en el país sino también en otros países tanto vecinos como lejanos, ya que formaba parte de los sucesos ocurridos. Ha sido responsable de los cambios políticos como sociales en los países árabes. (Randa Achmawi, 2011).

\section{Participación positiva de la mujer tunecina en la fase de posrevolución}

El papel de la mujer tunecina durante y después de la sublevación de "Jasmin" ha sido esencial y más que evidente. Estuvo marcada por la presencia masiva de la mujer en las primeras filas de manifestaciones y protestas contra la injusticia y la corrupción. Aunque goza de muchos derechos sagrados desde hace siglos estipulados en el Código de Estatuto Personal, ha mostrado su interés en salir a las calles y defender sus derechos y trazar su nombre con letras de oro en estos momentos históricos.

Ante esta situación, la presencia femenina ha mostrado de nuevo la intención de la sociedad tunecina por conservar los logros realizados y, garantizar más su participación tanto en la vida política como social. Así, el 20 de abril de 2011 dio lugar a la adopción de un principio presentado por las asociaciones feministas que otorga la paridad de género en las elecciones de la Asamblea Constituyente del 24 de julio de 2011. (Randa Achmawi, 2011).

\section{Participación masiva de la mujer en las elecciones}

Consciente de su papel tan relevante antes y durante la revolución, la mujer quería dejar una huella en esta fase tan sensible, después de haber conseguido un éxito inesperado. Gracias a 
su participación, la sublevación ha triunfado y se ha convertido en un modelo democrático y estable a seguir en comparación con las demás revueltas surgidas en aquella época.

El despertar de 2011 dio lugar a una participación masiva de la mujer tanto en las calles como en los puestos directivos, y esto se explica por la base legislativa que otorgaba muchos derechos a la mujer desde hace décadas, ya que en este país se respetan. El 26 de enero de 2014 se aprobó una nueva constitución que reemplazó la antigua que fue aprobada en 1956, meses después de la independencia. Este texto se considera como uno de los textos más avanzados del mundo árabe, en él se garantiza entre otros, los derechos tanto personales como colectivos de las personas.

La mujer tunecina protagonizó la escena política durante los cinco años después de la revolución, la denominada "transición democrática", que ha contribuido en el desarrollo tanto de las elecciones legislativas como presidenciales que tuvieron lugar en nuestro país de dos formas, la primera como votante y la segunda como participante. Según las estadísticas del Instituto Nacional de Estadísticas, la mujer alcanza el 47\% de los inscritos en el registro de votantes, contra una participación moderada del hombre de 53\%.

El mismo informe elaborado en 2015, detalla también que la mujer ha participado como miembro de oficina de voto con un porcentaje del $49 \%$, mientras que como presidenta de voto desciende al $30 \%$. Y como candidata la mujer solo representa $26 \%$ frente al hombre con un $74 \%$. En cuanto a su presencia como observadora durante el proceso electoral en organizaciones no gubernamentales, la mujer constituye $42.5 \%$ de los observadores según la misma fuente.

Analizando esta relación de estadísticas de la presencia femenina durante el proceso electoral destacamos dos observaciones, la primera consiste en que la mujer cuenta con mayor presencia en la estructura global de las elecciones como votante, observadora... mientras que como presidenta de oficina o candidata solo representa el tercio de los participantes. La segunda consiste en que este retroceso en las estructuras directivas revela que a pesar de este avance legislativo, la mujer se ve relegada a segundo plano o que ella misma evita ese cargo.

En la esfera política la mujer encabezó muchos partidos políticos y puestos directivos que antes eran monopolizados por los hombres. De hecho, la presencia femenina en la Asamblea Nacional Constituyente, alcanzó solo 26,7 \% en 2011, mientras en 2014 y tras las elecciones legislativas este porcentaje ha subido hasta el 31,3\% de los diputados (casi un tercio).

En este contexto según el Instituto Nacional de Estadística, durante estos últimos cinco años después de la revolución tunecina, se ha registrado un número muy reducido de mujeres que han podido ocupar puestos ministeriales. Éstas han sido entre 2 y 3 mujeres cada año, excepto en 2015 y durante el mandato de Habib Essid donde la presencia de la mujer como ministra ha aumentado hasta llegar a 8 mujeres con un porcentaje de $19,5 \%$ del formato gubernamental. Aunque consideramos un porcentaje bajo es la primera vez que llega a este porcentaje.

A continuación, es bueno mencionar que estas estadísticas ilustran una presencia casi notable del sexo femenino en la transición democrática del país y un papel relevante durante todo el 
proceso transitorio después de la sublevación. Pero estas mismas fuentes ocultan una realidad y revelan diferencias flagrantes e injustas, sesgos en los porcentajes y a veces datos inexistentes.

\section{Conclusiones}

Las fuentes consultadas en el presente trabajo, son de doble naturaleza. De un lado, hemos recurrido al Código del Estatuto Personal (CEP) texto promulgado a mediados del siglo pasado que regula la situación jurídica de la mujer y el derecho de la familia en general. La política emancipadora se basa en otro texto que es la Constitución de la República Tunecina, donde se estipula entre otras cuestiones, la igualdad ante la ley de hombres y mujeres. Añadir a ello, la nueva Constitución aprobada en 2014 que también, garantiza los derechos de género. Así pues, hemos comparado estadísticas de institutos tunecinos, las del Instituto Nacional de Estadísticas (INE), y otras fuentes como la de la Organización de Naciones Unidas. De otro lado, hemos analizado los artículos escritos sobre este tema, y, otros trabajos escritos o libros, que estudian en general la situación de la mujer en el mundo islámico-árabe y, en particular en Túnez.

La mujer tunecina goza desde la independencia hasta la actualidad de una plataforma legislativa, el Estatuto Personal de 1956, la Constitución Tunecina de 1959, otras leyes a favor de la mujer, la Constitución de 2014 que le reconoce la igualdad ante la ley... entre otras. Que le permite gozar de sus derechos tanto civiles como políticos igual al hombre, como el derecho a voto, la abolición de la poligamia, la instauración del divorcio legal, aparte del derecho al aborto... entre otros.

El proceso emancipador de la mujer tunecina hubiera sido difícil sin la voluntad de la sociedad civil tunecina encabezada por el presidente Habib Bourguiba (1956-1987) que protagonizó esta política revolucionaria mediante una política moderna a favor de la mujer, promulgando leyes que aseguran su igualdad ante la ley. Otra figura, fue el pensador Taher Haddad 1930, quien también se alzó para reivindicar la emancipación de la mujer tunecina apelando a su libertad, mediante un discurso moderno, traduciendo estas ideas en un libro llamado "Nuestra mujer: la legislación islámica y la sociedad", en el cual apeló a la escolarización de la mujer y otras cuestiones.

A pesar de este análisis, existen carencias en las fuentes: en cuanto a continuidad, uniformidad, procedencia... pero presentan datos importantes de la participación feminista en la construcción del proceso democrático y, su presencia antes y después de la primavera árabe.

En el mismo contexto, la mujer tribal cuenta con muchas carencias y se siente desfavorecida, sobre todo las mujeres de las provincias interiores del país y que residan en las zonas fronterizas con Argelia, así como, el noroeste del país, provincias como Beja, Jendouba, Kef, Gasserine... entre otras. En estas zonas la tasa de alfabetismo registrada es muy elevada y, la inserción de la mujer en la vida pública es mucho menor.

Durante la transición democrática, la mujer tunecina ha mostrado su interés junto al hombre en mantener los objetivos de la sublevación, participando en la elaboración del borrador de 
la constitución, tanto en las elecciones legislativas presidenciales de 2014, como en la participación notable de una nueva construcción social. Estos hechos y otros le han convertido, sin lugar a dudas, en la protagonista de la primavera árabe de su época.

La mujer tunecina rompió todas las barreras sociales para alcanzar sus propósitos saliendo a las calles gritando y rechazando las políticas de tiranía y las injusticias del Estado. Una buena táctica, el coraje y la intuición de la mujer le han convertido en uno de los modelos a seguir en el mundo árabe y africano.

Como hemos visto durante el planteamiento de los datos, referidos a la participación de la mujer en los principales sectores del Estado tanto económico como político, este colectivo marca su presencia en grado muy alto. De hecho, el porcentaje de la inserción de la mujer tunecina en la vida activa según las últimas estadísticas es el más elevado en el mundo árabe.

A pesar de estos logros realizados desde hace décadas, la mujer tunecina sigue luchando para trazar su camino y su integración plena. Aunque que quedan cosas por hacer, está caminando para lograr la igualdad. Este proceso se opone a un antiguo dicho muy popular que considera que el verdadero lugar de la mujer es su hogar "las mujeres pertenecen solo a sus hogares y maridos", a lo largo de estos años la mujer tunecina ha mostrado su capacidad de romper estos estereotipos y borrar estas creencias.

Durante todo el proceso de emancipación hasta la actualidad la mujer tunecina ha mostrado su interés de liberarse, luchando contra muchas corrientes desagradables que la han relegado a un segundo plano, un proceso duro y complejo que la cuestiona para lograr muchos éxitos y que sin embargo le permitió protagonizar un papel feminista en el mundo árabe, privilegiada de derechos que garanticen su acceso a la vida pública.

\section{Referencias}

Achmawi, R. (2011) El papel de las mujeres en la Primavera Árabe. Panorama de actualidad, 273-281. Recuperado de http://www.iemed.org/-8MTV

Farhat, Z. (2005). Estatuto de la mujer tunecina: conciencia de ciudadana y responsabilidad de Estado. El avance de la mujer en Túnez es un instrumento de modernización sin el cual el país no podrá despegar. AFKAR/IDEAS, 45 - 47. Recuperado de http://cort.as/-8MT9

Montoro, R . (1992). La mujer tunecina en busca de un papel social: la obra literaria de 'Arūsiyya al-Nālūtī. Miscelánea de Estudios Árabes y Hebraicos. Sección ÁrabeIslam, 41, 235-247. Recuperado de: http://cort.as/-8oYX

Sahli, K. (2001). La Literatura Tunecina Desde La Independencia Hasta Hoy. Estudios Humanísticos de Filología (23),369-375. Recuperado de: http://cort.as/-8MVH 


\section{Webgrafía}

Ben Achour, S. (2014). La nueva constitución de Túnez: un avance decisivo para los derechos de las mujeres. $O N U$. Recuperado de: http://cort.as/-8oXz

Caridad, R. (1995). El Código Tunecino de Estatuto Personal. 2017, de ACADEMIA Recuperado de: http://cort.as/-8oYP

Cembrero, I. (2011). Las mujeres tunecinas han tenido un papel clave en la lucha contra Ben Ali. La policía secreta manipuló vídeos pornográficos con el rostro de las disidentes. El País, Recuperado de: http://cort.as/-8oXq

Díaz, P. (2011). Luces y sombras de la mujer tunecina. El Mundo, Recuperado de: http://cort.as/-8oYe

Galindo, N. (2017). Túnez con acento de mujer. $V R \& F$ Recuperado de: http://cort.as/-8oYs

Kalboussi, M. (2015). La femme dans la vie publique: Cas de la participation féminine aux élections législatives de Túnez: un avance decisivo para los derechos de las mujeres. De Nawaat. Recuperado de: http://cort.as/-8oYL

Lavaissiere, D. (2014). La nueva constitución tunecina garantiza la igualdad entre los géneros. UNFPA. Recuperado de: http://cort.as/-8oYB 